\section{Peoples of the Philippines}

THE war in the Philippines has not been forgotten, nor has the courageous part played by the Filipinos alongside their American allies. But the average individual knows little about the geography of the Philippines, and less about the folk who inhabit them. To remedy this state of affairs, the Smithsonian Institution has produced War Background Studies No. 4, "Peoples of the Philippines", by Herbert W. Krieger ; it contains 86. pages of interesting print, a number of well-chosen illustrations, and an extensive bibliography. An account of the topography, climate, and kindred subjects is given, but most of the work is devoted to a description of the people. As might be expected, they are for the most part very mixed in origin and are the result of more than one culture contact in the past. This is clearly apparent in the realm of religion, where it appears that many pagan Indonesian ideas and superstitions still persist, although the large majority of the inhabitants are Christians. The material culture of some of the more primitive tribes includes knives of various kinds, bows and arrows, and the blow gun. The darts in use with the latter are often poisoned, there resulting an exceedingly effective weapon for killing small game silently. Various types of houses are illustrated, and a description of the language given.: But anyone wanting to know more about these islands and their interesting inhabitants, who surely will have a not unimportant part to play in the post-war world in the Pacific, should read for himself about the islands and their inhabitants.

\section{New Farm Crops for Australia}

Australia possesses three main stations for testing the agricultural and horticultural suitability of various kinds of plants from other regions for Australian conditions. Pamphlet No. 114 of the Commonwealth of Australia Council for Scientific and Industrial Research (314 Albert Street, East Melbourne, Victoria), by A. McTaggart and T. B. Paltridge, gives details of some of the useful and outstanding species tested at the Lawes (Queensland) station, which has a sub-tropical .climate. Among the outstanding introductions is Stylosanthes guianensis, which appears to be capable of assuming the agricultural role of lucerne (Medicago sativa) under tropical conditions. The variety polia of $M$. sativa is also suitable. Two kinds of cocksfoot grass, Dactylis glomerata var. hispanica, from southern France, and a strain from Algeria, also appear among the outstanding introductions. Details of the yield of Paspalum scrobiculatum, Urochloa pullulans, Panicum maximum and Rhodes grass are given, and indicate higher potential yields than are obtained from present grassland. Phaseolus lathyroides, a shrubby legume from tropical regions, has been found to behave as a slender twining plant when associated with grasses, and indicates the necessity for imagination and insight when testing the suitability of new plants.

\section{Research on Cancer}

AMONG the numerous laboratories and institutions engaged in cancer research throughout the British Empire, none has a higher reputation than the Royal Cancer Hospital and its associated Chester Beatty Research Institute. We therefore welcome the republication in one attractive volume of a selection of papers which issued from these laboratories during the period 1935-39 (London : Royal Cancer Hospital (Free). 16s.). These had previously been published in many different journals in Britain and the United States, and their assembly will prove of great convenience to many workers in this field. Greatest importance will probably be attached to the series of papers by Prof. E. L. Kennaway and his colleagues on the synthesis and properties of carcinogenic compounds, which probably embodies the most notable contribution to cancer research during the last decade. Other valuable papers deal with the physical aspects of low-voltage, high-voltage and radium therapy and with topics concerning the pathology of cancers. The Institution is to be congratulated on this fine record of its work.

\section{Venereal Disease Control}

IN an address delivered at the Third Pennsylvania Health Institute (Med. Rec., New York, Jan. 1943) Colonel Edgar Erskine Hume states that, during the War of 1914-18, General Pershing issued orders to the American Expeditionary Forces on the following lines: $(a)$ education in sex hygiene and the nature and prevention of venereal diseases ; $(b)$ prophylaxis ; (c) physical examinations; (d) repression of prostitution; (e) reporting sources of infection with dispensary treatment of infected civilians where possible ; (f) court martial of men who contracted venereal disease ; and $(g)$ treatment of venereal disease at the front, thereby removing any possible temptation of men to become infected, and so get sent to the base. Although Pershing's programme did much good and was far in advance of that of any other country, seven million days of service were lost and a total of 338,746 soldiers were treated for venereal disease. In spite of the large number of cases, venereal disease is less prevalent in the army than in corresponding civil life. The rate of venereal disease in the United States Army has been reduced from 175 per 1,000 in 1904 to about 34 or 36 , and has never been above 50 since 1926.

\section{Murine Typhus in Bogotá}

IN a preliminary note (Bol. Of. San. Panam., 21,1090 ; 1942) on this subject, Dr. Luis PatinoCamargo, director of the National Institute of Epidemiology and Medical Research at Bogotá, states that to date eight strains of the typhus rickettsia type have been found and classified in Colomba. $\mathrm{He}$ maintains that all these forms may be reduced to epidemic typhus, murine typhus and Tobia spotted fever. In three different places in Bogotá cases of typhus have occurred apparently caused by an endemic virus carried by fleas and maintained in wild rats. The writer, therefore, concludes that an intensive attack should be undertaken in Bogoté against these animals.

\section{Standardization of Overhead Power Supply Lines}

H. Willott Taylor and K. L. May, in a paper entitled "Standardization in Great Britain of SingleCircuit Overhead Lines up to $33 \mathrm{kV} . "$, presented recently in London before the Institution of Electrical Engineers, consider that standardization can be done in a rational manner which will avoid any likelihood of stultification of new ideas ; the preparation of suitable standard designs of overhead lines could be undertaken by a standing committee of the British 